\title{
A review of the influence of fathers on children's eating behaviours and dietary intake
}

\author{
Stephanie Rahill \\ Technological University Dublin, stephanie.rahill@tudublin.ie \\ Aileen Kennedy \\ Technological University Dublin, aileen.x.kennedy@tudublin.ie \\ John Kearney \\ Technological University Dublin, john.kearney@tudublin.ie
}

Follow this and additional works at: https://arrow.tudublin.ie/scschbioart

Part of the Biochemical Phenomena, Metabolism, and Nutrition Commons, Dietetics and Clinical Nutrition Commons, Family Medicine Commons, and the Other Food Science Commons

\section{Recommended Citation}

Stephanie Rahill, Aileen Kennedy, John Kearney, A review of the influence of fathers on children's eating behaviours and dietary intake, Appetite, Volume 147, 2020, 104540, ISSN 0195-6663, DOI: 10.1016/ j.appet.2019.104540.

This Article is brought to you for free and open access by the School of Biological Sciences at ARROW@TU Dublin. It has been accepted for inclusion in Articles by an authorized administrator of ARROW@TU Dublin. For more information, please contact arrow.admin@tudublin.ie, aisling.coyne@tudublin.ie,gerard.connolly@tudublin.ie. Funder: Department of Agriculture Food and Marine

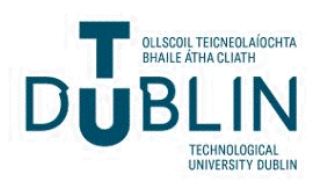




\title{
A review of the influence of fathers on children's eating behaviours and dietary intake
}

\author{
Stephanie Rahill*, Aileen Kennedy, John Kearney \\ School of Biological Sciences and Health, Technological University Dublin, City Campus, Dublin, Ireland
}

\section{A B S T R A C T}

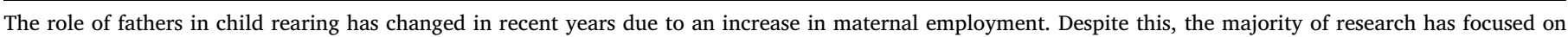

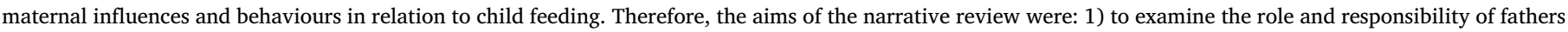

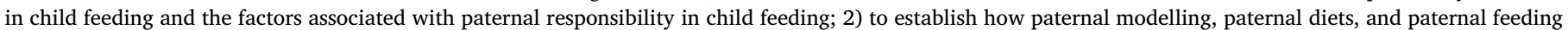

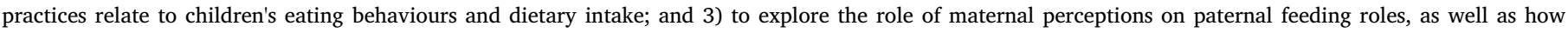

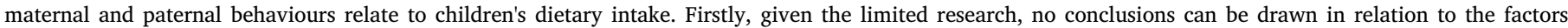

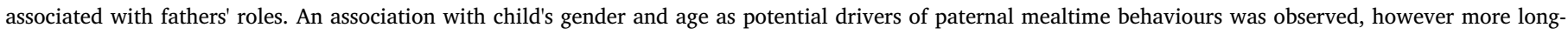

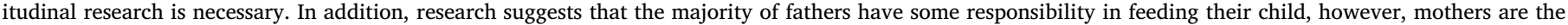

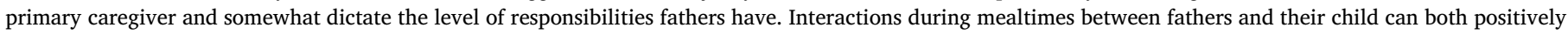

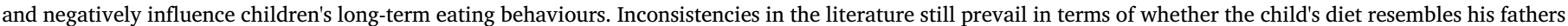

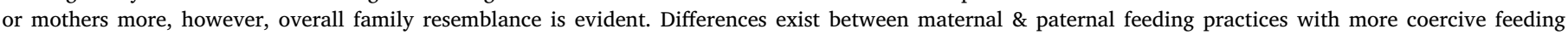

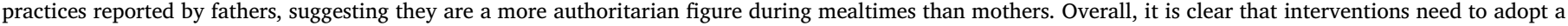
whole-family approach when tackling children's lifestyle behaviours in order to address the differential influence of both parents.

\section{Introduction}

Families are complex interactive systems, containing numerous individuals across a series of contexts, which collectively influence children's developmental outcomes (May, Chai, \& Burrows, 2017). The definition of a family has evolved over the years due to changes in household composition and living arrangements. In the late 1940s, George Murdock defined the family as "... adults of both sexes at least two of whom maintain a socially approved sexual relationship and one or more children owned or adopted of the sexually cohabiting adults" (Murdock, 1949). Whereas the most recent definition is more generalised: "A family 'nuclei' is constituted when two persons (of either sex) choose to live together as a married couple, in a registered partnership, or a consensual union, whether or not they have children; single parents with children also constitute a family unit, while people living alone do not, nor do groups of unrelated people who choose to share a house together" (eurostat, 2017). However, while definitions of the family outline the composition of the family unit, they do not explicitly state what the role is of each family member. Particularly those of the adult members, which should be understood to establish how the family, as a collective unit, influences children's development.

The fathers' role within the family has evolved dramatically over the last century. Fathers are increasingly spending more time with their children due to high maternal employment (Bianchi, 2000). The increase in maternal employment has resulted in a rise in fathers' parenting responsibility, which may positively influence children and families (Pleck \& Masciadrelli, 2004). With fathers having more caretaking responsibility, fathers' engagement in child-rearing and patterns of co-parenting have grown (Feinberg, 2003). Such that the once 'traditional' roles of mothers and fathers have evolved to both parents having joint or overlapping responsibilities within the family.

Studies suggest that the quality of the co-parenting relationship has an independent influence on maternal/paternal influences on the child's development (May et al., 2017; Morgan et al., 2017). However, this shift in roles and responsibilities has not yet fully transitioned into research or behaviour-change interventions. Morgan et al. (2017) conducted a systematic review of randomised control trials (RCTs) assessing behavioural interventions to treat or prevent obesity (Morgan et al., 2017). Findings revealed that in RCTs who required only one parent to participate, fathers only represented $6 \%$ of parents (Morgan et al., 2017). Following on from this, in RCTs where both parents could participate, 92\% did not report findings from fathers (Morgan et al., 2017). A similar review was conducted by Davison et al. (2018), with findings from this systematic review highlighting the lack of father participation in interventions, especially in younger children, and suggest that theories focusing on the family as an entire unit may help

\footnotetext{
* Corresponding author.

E-mail address: stephanie.rahill@tudublin.ie (S. Rahill).
} 


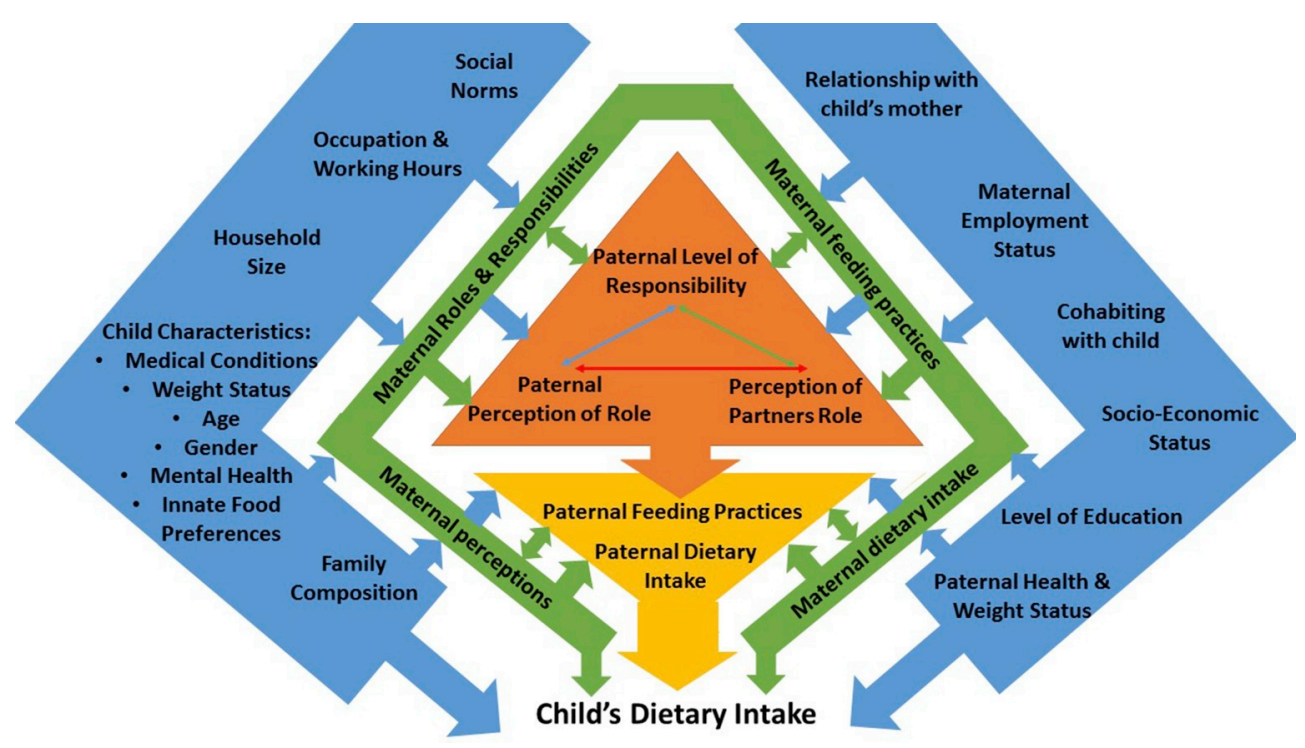

Fig. 1. Conceptual framework on the influence of fathers on child's dietary intake.

support father participation (Davison et al., 2018).

The family systems theory perspective implies that a child's development of eating behaviours can be influenced by both the child's individual interactions with other family members and the relationship between other family members (Minuchin, 1985; Pulley et al., 2014). Evidence to date suggests that there are minimal differences between mothers and fathers ability to rear their children, or tend to their physical needs, except for breastfeeding (Spinney, 2011). While research on fathers' involvement and influence in a child-feeding domain has been investigated, it has not been investigated to the extent that it has been in mothers. Therefore, the aims of this narrative review were: 1) to examine the role and responsibility of fathers in child feeding and the factors associated with paternal responsibility in child feeding; 2) to establish how paternal modelling, paternal diets, and paternal feeding practices relate to children's eating behaviours and dietary intake; and 3 ) to explore the role of maternal perceptions on paternal feeding roles, as well as how maternal and paternal behaviours relate to children's eating behaviours and dietary intake.

The aims of this review are illustrated in more detail in Fig. 1. The sections that explain the first and second aim are represented by the yellow, orange and blue backgrounds, such that numerous factors that are components of a father's individual, household, and community life (blue) influence fathers role/responsibility (orange) and behaviours during mealtimes (yellow), which collectively can influence children's dietary intake. The third aim is represented by the green, orange and yellow backgrounds. Firstly, following the unidirectional green arrow, maternal perceptions and behaviours (green) influence fathers roles (orange) and behaviours during mealtimes (yellow). Secondly, the bidirectional green arrow suggest that there is a potential association between maternal and paternal factors that can collectively influence child's dietary intake. Therefore, to develop interventions that promote both mother and father engagement, it is essential to form an understanding of the roles and responsibilities of both parents in feeding their child and ultimately identifying differences in how each parents' behaviour can influence their child's dietary intake.

\section{Methodology}

A literature search for relevant peer-reviewed scientific articles was conducted using Science Direct, PubMed, and Google Scholar between July to December 2018. "Limit to English language" and "remove duplicates" were applied to all searches. Combinations of some of the following key search terms (not exclusive) were used for individual searches, with only specific words used in relation to each section of this review: fathers/paternal/dad, breastfeeding, role, responsibility, paternal/maternal/parental feeding practices, family mealtimes, food consumption, resemblance, dietary/food intake, children's eating behaviours, mothers/maternal, comparison. For example, the search about fathers' role in child feeding would contain the following (father OR paternal OR dad) AND (role OR responsibility OR involvement) AND (child feeding OR feeding practices OR family mealtimes). In addition, further studies were identified from the reference list of the included studies.

Inclusion criteria: Articles were considered if they were available in full text in a peer-reviewed journal and were in English, up to December 2018. Both quantitative and qualitative studies were included in this narrative review. The age range of studies included was from birth to 18-years-old. Tables were created to give an overview of the studies discussed in each section. However, some studies were utilised in more than one study and therefore were assigned to a table based on when they first appeared in the literature.

\section{Results}

In line with the aims of this narrative review, the results section was divided into three overarching topics, all of which form an important component in fathers' involvement in child feeding: fathers' responsibility and role in child feeding; fathers' behaviours during mealtimes; and maternal perceptions and behaviours in the context of paternal feeding responsibilities and feeding practices. Within each of the three sections, the overarching topic was elaborated on, which lead to the creation of sub-sections. Therefore, the results are presented by an outline and summary of the studies included, followed by a table for the three sections, that includes the relevant information on each study included.

\subsection{Fathers' responsibility and role in child feeding}

The results of studies investigating fathers' perceived responsibility and role in child feeding are presented in Table 1. A father's role in the upbringing of his child is more loosely defined by society than a mother's role, with a father's perception of his role a potential driver of his behaviour (Parke, 2008; Tamis-Lemonda \& Cabrera, 1999). The type of interactions a mother and father have with their child are likely to be unique but may also be contrasting with one another, such that a father's behaviour may contribute to the child's development in an 


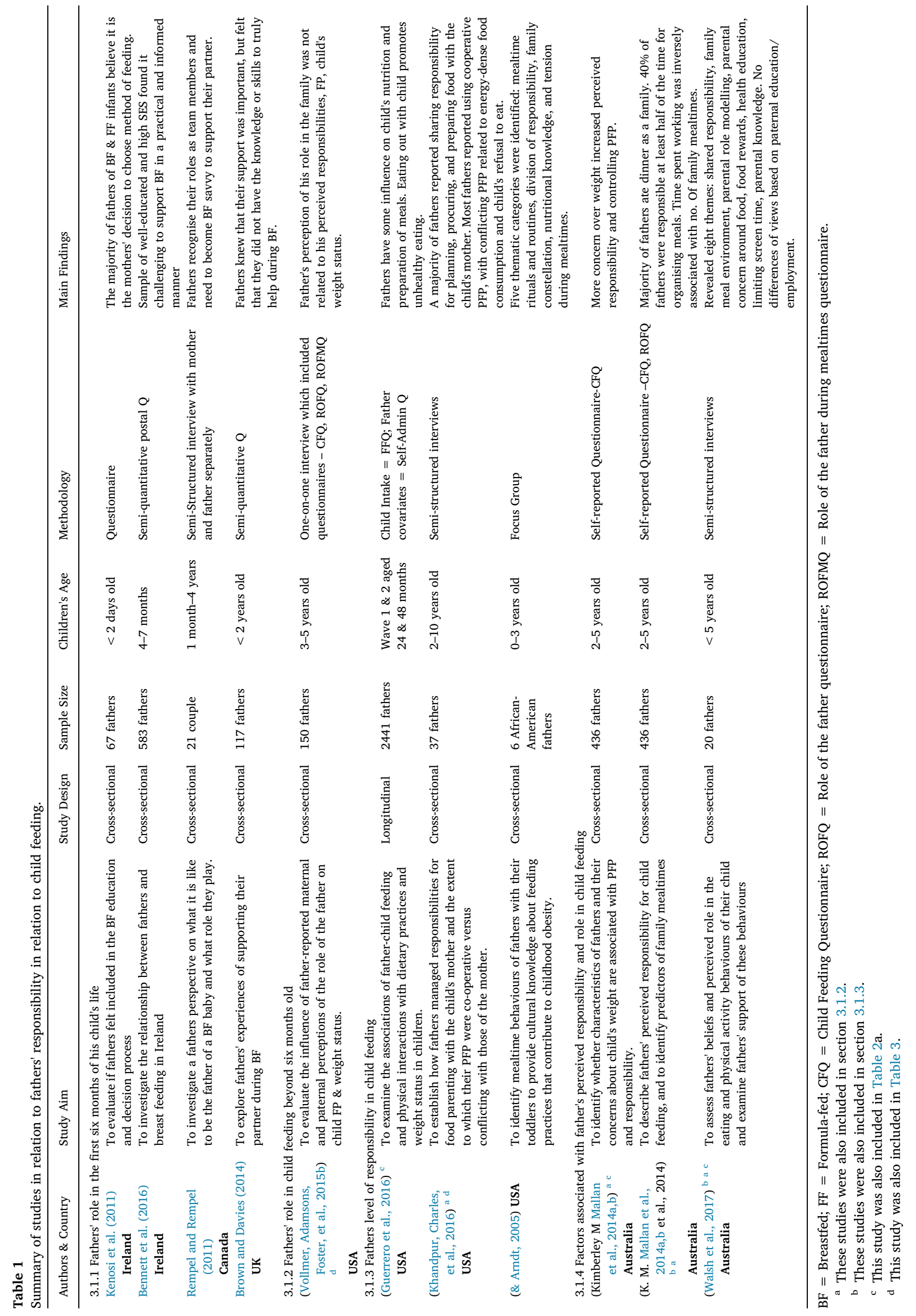


alternative way from the child's mother (Doherty, Kouneski, \& Erickson, 1998; Pulley et al., 2014). Therefore, in order to understand how fathers' role in child feeding influences children's development we need to explore the progression of his roles and responsibilities from infancy to later childhood. In addition to exploring the level of paternal involvement and responsibility and establishing the factors that may contribute to differing levels of involvement and responsibility.

\subsubsection{Fathers' role in the first six months of his child's life}

Firstly, it is important to take into consideration the foundations of parental roles as this may help understand how roles evolve throughout a child's life from birth to adulthood. Worldwide, one of the many decisions new parents face is whether to breastfeed or formula-feed their new-born baby, with the mother naturally having the ultimate say, according to $75-80 \%$ of fathers (Bennett, McCartney, \& Kearney, 2016, pp. 169-176; Hansen, Tesch, \& Ayton, 2018; Kenosi et al., 2011). Therefore, from the onset fathers are the secondary decision-makers about the earliest dietary intake of their child, which may perhaps influence their future feeding practices decision making. There are different feeding responsibilities between the mother and father depending on whether the infant is breastfed or formula-fed. The feeding routine for formula-fed infants has the opportunity to be shared between both parents, with shared responsibility between parents more difficult with breastfed infants, even with the availability of breast pumps. Therefore, the fathers' role of a breastfed infant, in terms of feeding, is ultimately that of a support person. The role as a support person is of utmost importance, with evidence suggesting that fathers support for their breastfeeding partner is an important component in ensuring a positive breastfeeding experience for both the mother and child (Brown \& Davies, 2014; Rempel \& Rempel, 2011). Overall, despite this it is commonly reported by fathers that breastfeeding can make fathers feel left out or unimportant in the child's life and deprive them of bonding time with their child (Bennett et al., 2016, pp. 169-176; Rempel \& Rempel, 2011). Overall, it is clear that the role of fathers of breastfed infants differ to the role of fathers of formula-fed infants, in terms of having a choice whether to be physically involved or not. Research needs to establish whether fathers' role of the breastfed infant during complementary feeding and later childhood differ to the fathers' role of formula-fed infants.

\subsubsection{Fathers' role in child feeding beyond six months old}

Both quantitative and qualitative studies have gained insight into fathers' role in child feeding. However, given the nature of qualitative studies, they have provided more information given the descriptive subjective responses. The quantitative studies to date have used the perceived responsibility subscale of the Child Feeding Questionnaire (CFQ) (K. M. Mallan et al., 2014a,b; Kimberley M Mallan et al., 2014a,b; Vollmer, Adamsons, Foster, et al., 2015b) and the Role of The Father Questionnaire (ROFQ) (K. M. Mallan et al., 2014a,b; Vollmer, Adamsons, Foster, et al., 2015b). The ROFQ was further adapted by Vollmer and colleagues to become the Role of The Father at Mealtimes Questionnaire (ROFMQ) (Vollmer, Adamsons, Foster, et al., 2015b). The ROFQ assesses fathers' beliefs about their general attitude and involvement in their child's upbringing and therefore it is difficult to understand fathers' involvement in feeding when using this questionnaire independently. However, both studies that used this tool have explored the mean score of the ROFQ in aspects of child feeding. According to the title of the paper by (K. M. Mallan et al., 2014a,b) and the subsequent analysis conducted, 'the frequency of meals with child' was the dependent variable and thus suggests that this is the extent of fathers role in child feeding. The mean subscales scores of both the ROFQ and ROFMQ were examined in relation to paternal perceived responsibility and paternal feeding practices, with only involvement during mealtime significantly associated (Vollmer, Adamsons, Foster, et al., 2015b). The findings in relation to paternal feeding practices give more insight into fathers behavioural roles during mealtimes, such that higher involvement was associated with lower reports of controlling feeding practices, with Vollmer and colleagues suggesting that high paternal involvement may be protective against child obesogenic behaviours (Vollmer, Adamsons, Foster, et al., 2015b).

The perceived responsibility subscales (CFQ) was used in the three quantitative studies (K. M. Mallan et al., 2014a,b; Kimberley M Mallan et al., 2014a,b; Vollmer, Adamsons, Foster, et al., 2015b) and gives a clear indication on fathers' level of responsibility on three important components of meal preparation: organising their child's meal, deciding their child's portion size and deciding the types of food served. Meal preparation is a large component of child feeding responsibilities, which can involve a lot of time and skills, depending on the type of meal being prepared. However, unfortunately, the data from these quantitative studies cannot provide this level of detail.

Findings from two qualitative studies somewhat elaborated on this, with fathers in these studies reporting that role sharing involved cooking and doing the grocery shopping with their partner (Khandpur, Charles, \& Davison, 2016; Walsh et al., 2017). In addition, a similar number of fathers reported dividing child feeding tasks with the child's mother, for example, some fathers reported that their partner was responsible for cooking while they were responsible for rules around mealtimes (Khandpur, Charles, et al., 2016). Findings from qualitative studies suggest that some child-feeding roles are shared among parents, with some clear distinct roles for both parents established within some families.

Exploring and defining the roles of fathers in a child-feeding context allows us to understand how paternal perceptions and behaviours can influences children's dietary intake. However, determining how often fathers occupy their child-feeding role must be explored as their level of responsibility may also influence children's dietary intake.

\subsubsection{Fathers level of responsibility in child feeding}

Mothers feel they have a greater responsibility in feeding their child (Daniels et al., 2013), with research suggesting that fathers have significantly lower perceived responsibility than mothers (Blissett, Meyer, \& Haycraft, 2006; Ek et al., 2016; Harris et al., 2018a; Pulley et al., 2014). Only five studies to date have tried to quantify and understand fathers' level of responsibility, which includes two quantitative studies (K. M. Mallan et al., 2014a,b; Guerrero et al., 2016) and three qualitative studies (Horodynski \& Arndt, 2005; Khandpur, Charles, et al., 2016; Walsh et al., 2017). Findings from quantitative research suggest that fathers have some level of responsibility in child feeding. More than half of fathers $(\sim 50 \%)$ of pre-school children reported being responsible at least half of the time for organising meals and deciding the quality and quantity of food offered to their child during mealtimes (K. M. Mallan et al., 2014a,b). With only a small proportion of fathers (10-16\%) reporting that they were rarely responsible for feeding their child (K. M. Mallan et al., 2014a,b). In addition, findings from this study show that higher paternal perceived responsibility and a positive attitude towards their role as a father was associated with a greater number of mealtimes per week with their child (K. M. Mallan et al., 2014a,b). These findings are supported by a large quantitative longitudinal cohort of American fathers of preschool children $(n=2441)$, which found that $43 \%$ of fathers had a great deal of influence on their child's nutrition and almost $50 \%$ of fathers reported daily involvement in preparing food for their child and assisting in their child's eating (Guerrero et al., 2016).

Although qualitative studies gained some further insight into fathers perceptions and attitudes towards their roles in child feeding, they also quantified the level of fathers' perceived responsibility based on responses. However, the quantification of responsibility levels need to be taken with caution due to the low sample size within the three studies (n < 37) (Horodynski \& Arndt, 2005; Khandpur, Charles, et al., 2016; Walsh et al., 2017). Khandpur and colleagues found that $62 \%(n=23)$ of fathers reported shared responsibility with their partner in respect to their child's dietary intake, with $16 \%$ of fathers reporting sole 
responsibility and the remaining $22 \%$ reporting that their partner was solely responsible (Khandpur, Charles, et al., 2016). Horodynski \& Arndt, (2005) found that $84 \%(n=5)$ of fathers in their study consumed a meal with their children at least once a day, with all fathers reporting that they participated in childcare activities either on a daily or weekend basis, which included food preparation, cooking, and feeding (Horodynski \& Arndt, 2005). Findings from the study by Walsh et al. (2017) suggest that the majority of fathers $(n=16 / 20)$ share the responsibility with their partners in relation to the dietary behaviour of their young children (Walsh et al., 2017). Overall, both quantitative and qualitative research suggests that the majority of fathers have some form of responsibility in feeding their child. Following on from this, we need to establish and explore the factors that influence a father's role and his level of responsibility in feeding his child.

\subsubsection{Factors associated with father's perceived responsibility and role in child feeding}

Limited research has been conducted in the feeding domain to establish the factors associated with perceived responsibility and/or paternal roles, with only two Australian quantitative studies addressing this topic directly (K. M. Mallan et al., 2014a,b; Kimberley M Mallan et al., 2014a,b). Both studies were conducted by Mallan and colleagues, with the aim of one study (Kimberley M Mallan et al., 2014a,b) to identify the child's and father's characteristics associated with fathers' perceived responsibility (CFQ). The first aim of the other study (K. M. Mallan et al., 2014a,b) was to describe the perceived responsibility and degree of involvement of fathers, with the second aim to investigate the predictors of how frequently fathers eat meals with their child. The two studies were conducted using the same cohort of Australian fathers of preschool children aged 2 to 5 -years-old $(n=436)$. Findings suggest that a father's role within the feeding domain is highly influenced by the number of hours they spend working, with fathers who spend more time in work having a significantly lower perceived responsibility in feeding their child (Kimberley M Mallan et al., 2014a,b). In addition to working hours, having an older child, higher socio-economic status, and concern for their child's weight were all significantly associated with increased paternal perceived responsibility for feeding, while child gender, paternal age, paternal BMI, and education level were not significantly associated (Kimberley M Mallan et al., 2014a,b). This study contributes to the limited research that has been conducted on determining the influence of SES on fathers' roles in feeding their children and consequently, the feeding practices utilised by fathers (Kimberley M Mallan et al., 2014a,b). Findings from (K. M. Mallan et al., 2014a,b) also found that fathers who spend more time in paid employment report fewer meals/week with their child. While higher levels of perceived responsibility and more engaging and involved fathers (High score ROFQ) report having more meals/week with their child (K. M. Mallan et al., 2014a,b). A child's age and gender, along with father's age, BMI and education were not associated with the frequency of meals/week with their child (K. M. Mallan et al., 2014a,b). Although not the primary aim of the qualitative study by Walsh et al. (2017), which interviewed twenty Australian fathers of preschool children, analysis of themes according to paternal education/employment revealed no substantial differences in the views of the fathers, in terms of shared responsibility, role modelling, and knowledge, to name a few (Walsh et al., 2017). Overall, given the inconsistent findings in terms of SES and education level in relation to paternal responsibility and roles, and as suggested in the systematic review by Khandpur et al. (2014); studies need to recruit fathers from diverse ethnicity/race, socioeconomic, and geographic backgrounds (Khandpur et al., 2014). In conclusion, findings from these studies suggest that a range of paternal and child factors influence fathers' level of responsibility.

Family mealtimes are a prime opportunity for roles and responsibilities to flourish and evolve. Therefore, it necessary to establish paternal behaviour during mealtimes, which primarily constitutes of paternal modelling and paternal feeding practices.

\subsection{Fathers behaviours during mealtimes}

Table 2a summarises studies exploring how fathers can influence children's dietary intakes during mealtimes in terms of paternal modelling and the resemblance between a father's and their child's dietary intake, while Table $2 \mathrm{~b}$ summarises the studies that focus on paternal feeding practices. Family mealtimes and the importance of them are a reoccurring theme within qualitative studies that investigated fathers' role in feeding their child. Walsh et al. (2017) found that Australian fathers of preschool children believe that mealtimes are an essential part of the "family social fabric", which allows them to share each other's company and develop family traditions (Walsh et al., 2017). Similarly, in the qualitative study by Horodynski \& Arndt, (2005) fathers believe that parental interactions with their child during mealtimes is a responsibility and the majority of fathers felt that mealtime routines and rituals were important (Horodynski \& Arndt, 2005). Within this study mealtime routines and rituals were defined as "those activities that encompass and govern the selection, preparation, and eating of food" (Horodynski \& Arndt, 2005). Family mealtimes give parents the opportunity to engage and interact with their child in a food-centred setting, which can allow the transfer of a father's knowledge and attitude towards foods via paternal modelling and paternal feeding practices. For the purpose of this review paternal modelling and familial resemblance of dietary intake will be discussed separately as current literature reveals that although a parent's and their child's diets are related, there is growing evidence to suggest that parental diet and parental modelling are two distinct constructs (Harris \& Ramsey, 2015; Larsen, Roel C J Hermans et al., 2015).

\subsubsection{Paternal modelling}

Parental modelling promotes observational learning, whereby children perceive their parents eating behaviours as the 'norm' which can influence their food intake leading to children adopting their parents eating behaviours (Bandura, 1977). Therefore, parental eating behaviours are a reference for what is appropriate behaviour, which can influence children's long-term consumption patterns in terms of food choice and quantity consumed (Herman \& Polivy, 2005; Larsen, Roel C J Hermans et al., 2015). Parental modelling occurs when a parent purposefully demonstrates healthy food choices and eating behaviours to encourage similar behaviours in the child; or a parent unintentionally exhibits unhealthy eating behaviours in front of the child (Vaughn et al., 2016). Within the current literature, many studies have focused on the influence of intentional modelling of healthy habits, as it is harder to assess unhealthy role modelling due to lack of awareness of these behaviours and greater likelihood of response bias (Vaughn et al., 2016). The systematic review and meta-analysis by Yee et al., (2017) revealed there was a strong positive association between parental modelling and both their child's healthy and unhealthy food consumption patterns (Yee et al., 2017). However, one must take into consideration that within this review that first, parental modelling also encompassed the parent's own food consumption behaviour (Yee et al., 2017). Secondly, of the eighteen studies that were included in the metaanalysis (role modelling healthy food only), five studies included fathers but they only represented a small proportion of the entire sample size (Brown \& Ogden, 2004; Cooke et al., 2004; Goldman, Radnitz, \& McGrath, 2012; Reinaerts et al., 2007; Wardle, Carnell, \& Cooke, 2005), with only one study solely focusing fathers only (Harris \& Ramsey, 2015). In addition, only one of the five studies exploring the association between role modelling and unhealthy food consumption (Yee et al., 2017) had a small sample of fathers $(n=15)$ (Brown \& Ogden, 2004).

As evident by the lack of studies included in the systematic review/ meta-analysis by (Yee et al., 2017), to date only two studies have directly assessed paternal modelling, with both using the Comprehensive Feeding Practices Questionnaire (CFPQ) (Harris \& Ramsey, 2015; Watterworth et al., 2017). The study by Harris and Ramsey (2015) (included in meta-analysis (Yee et al., 2017)) had a small sample size 


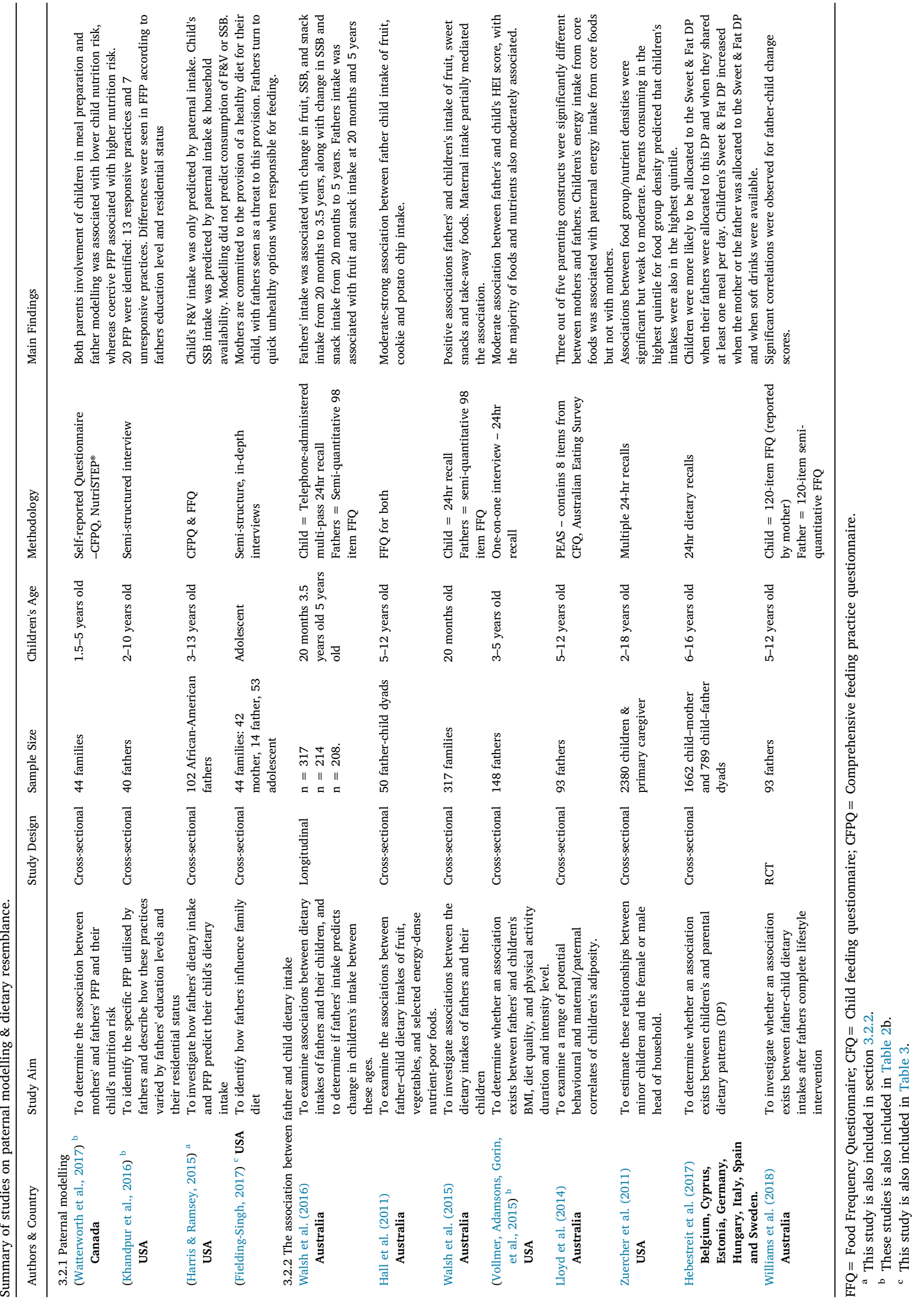




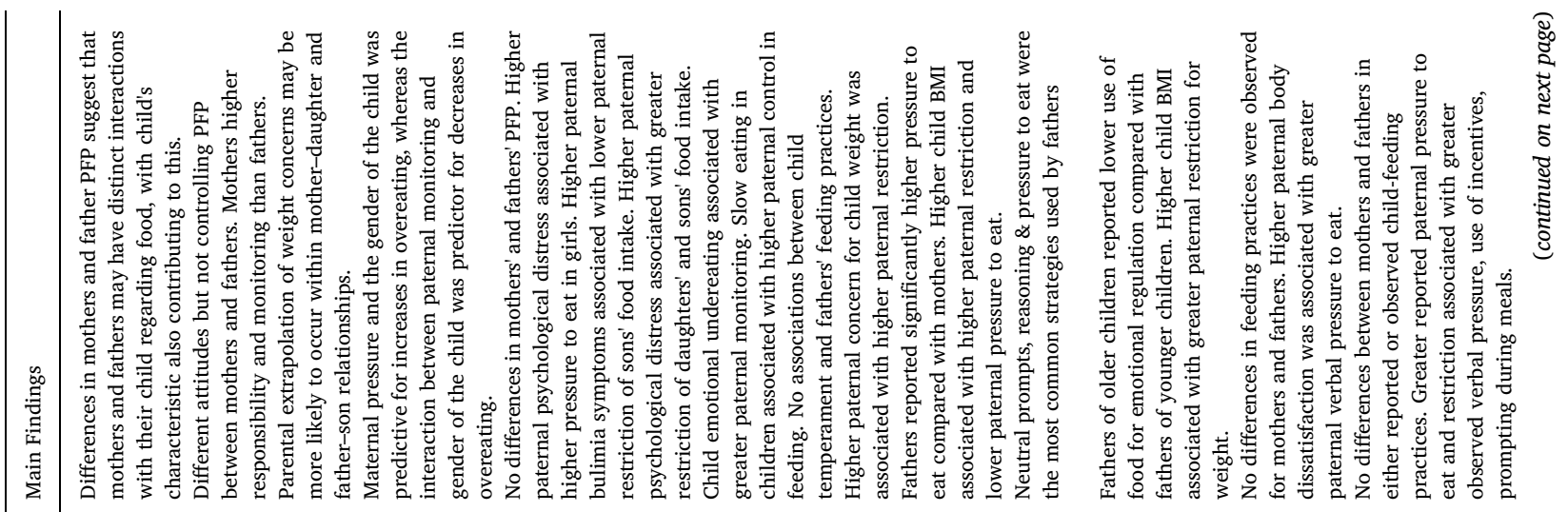

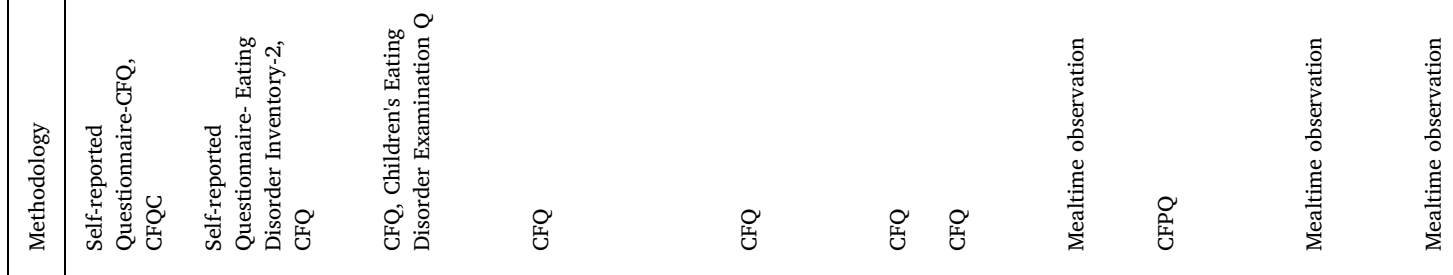

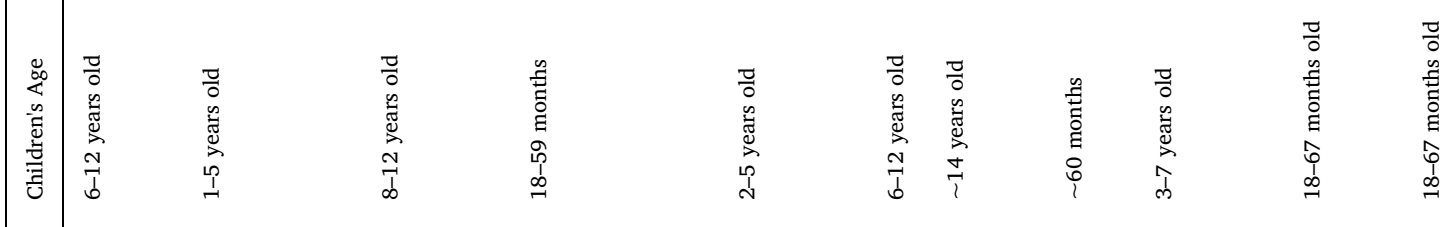

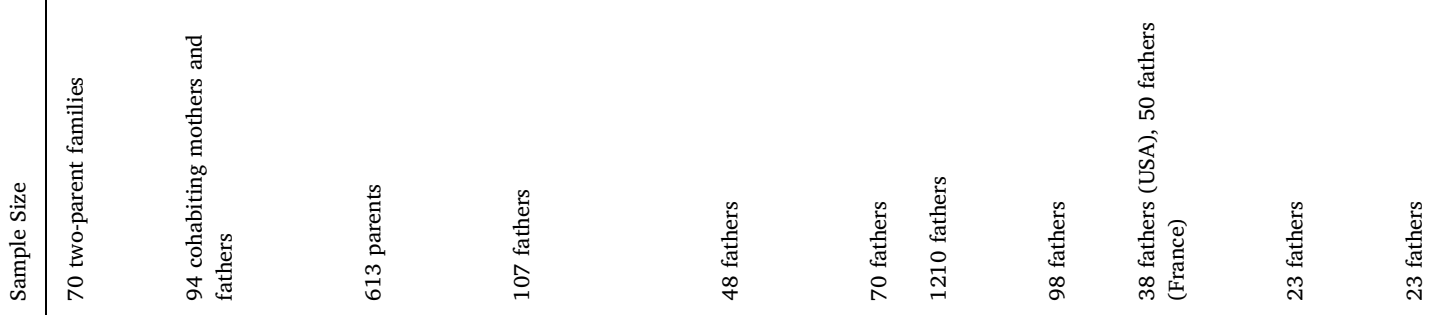

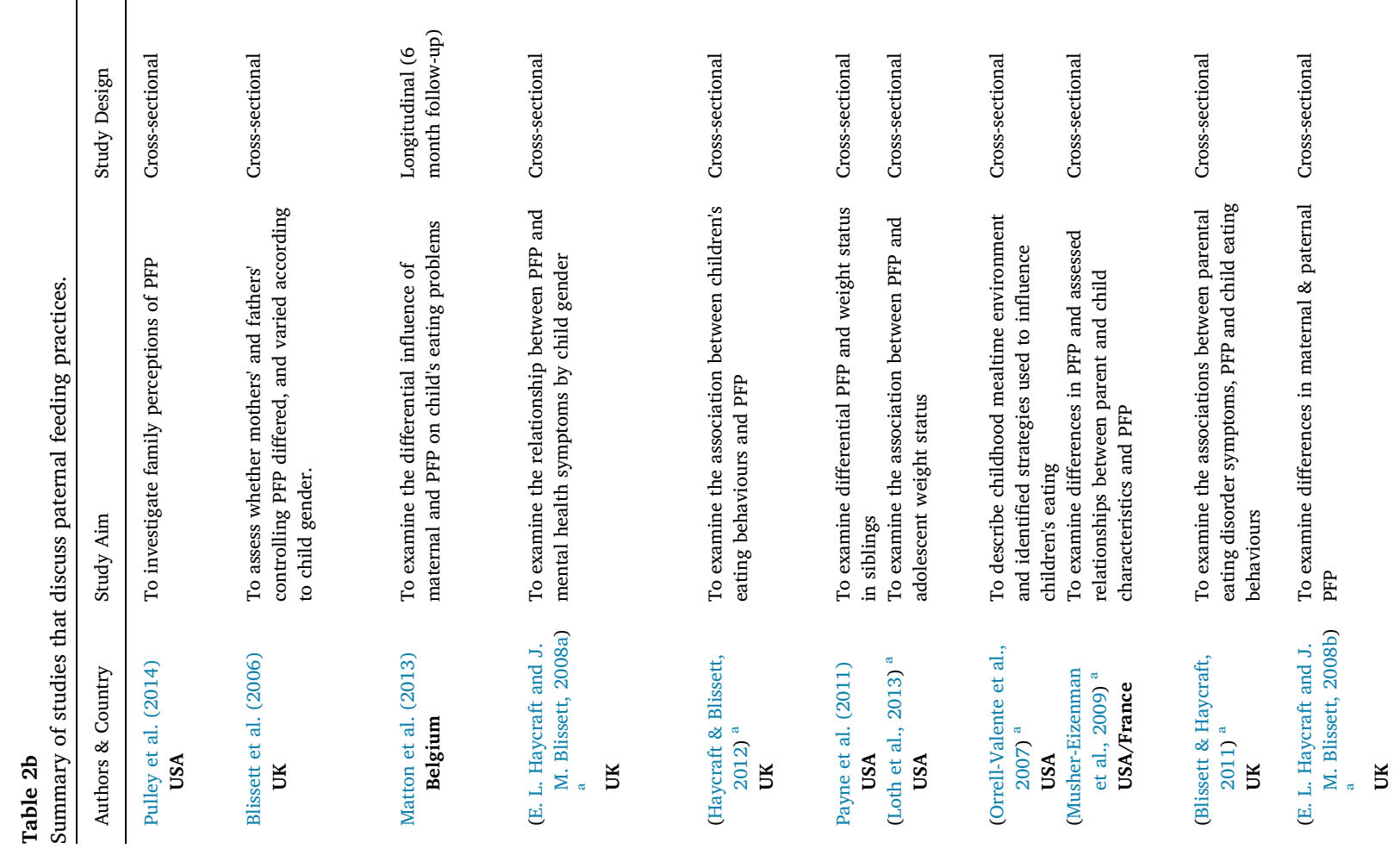




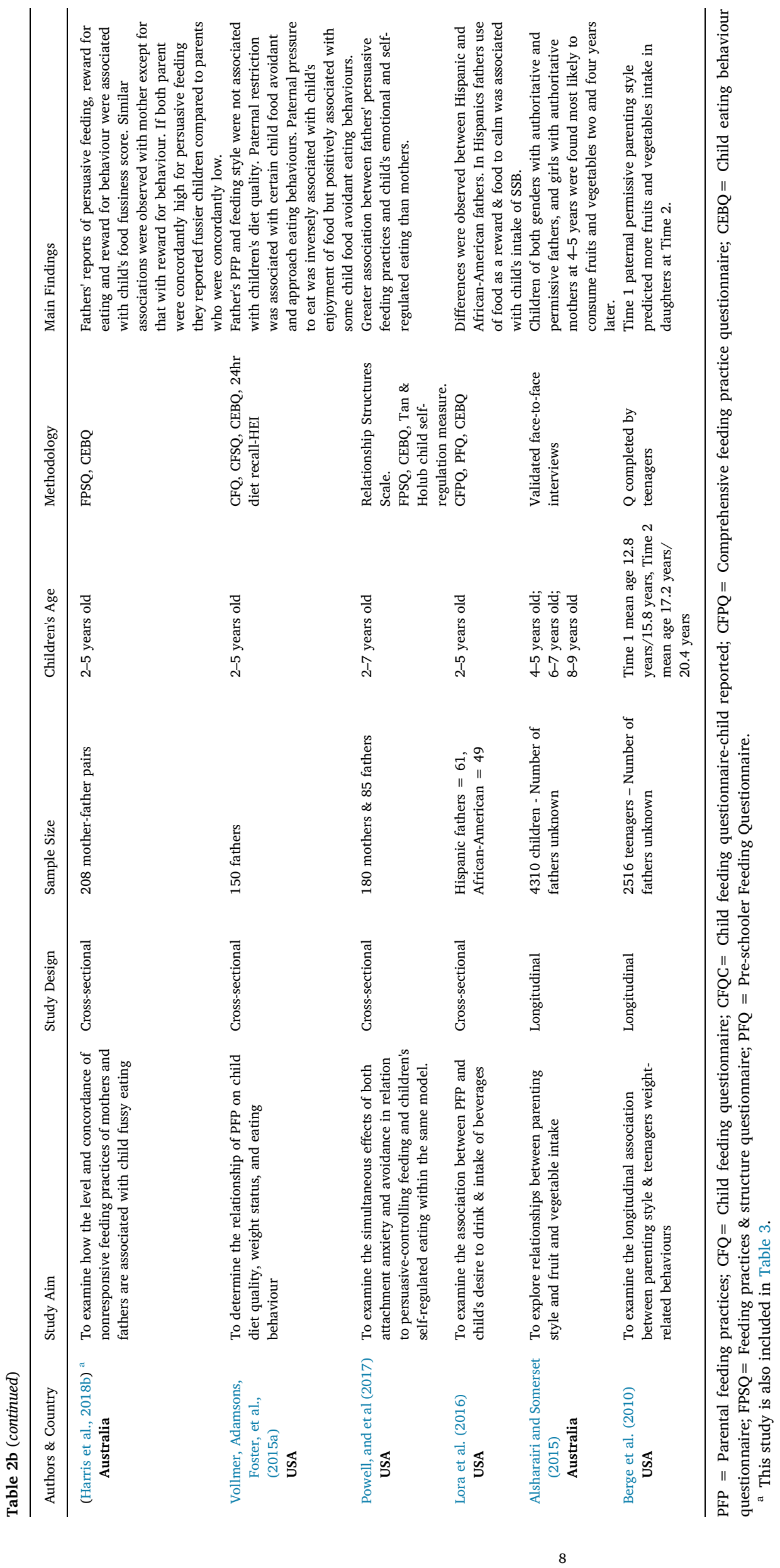




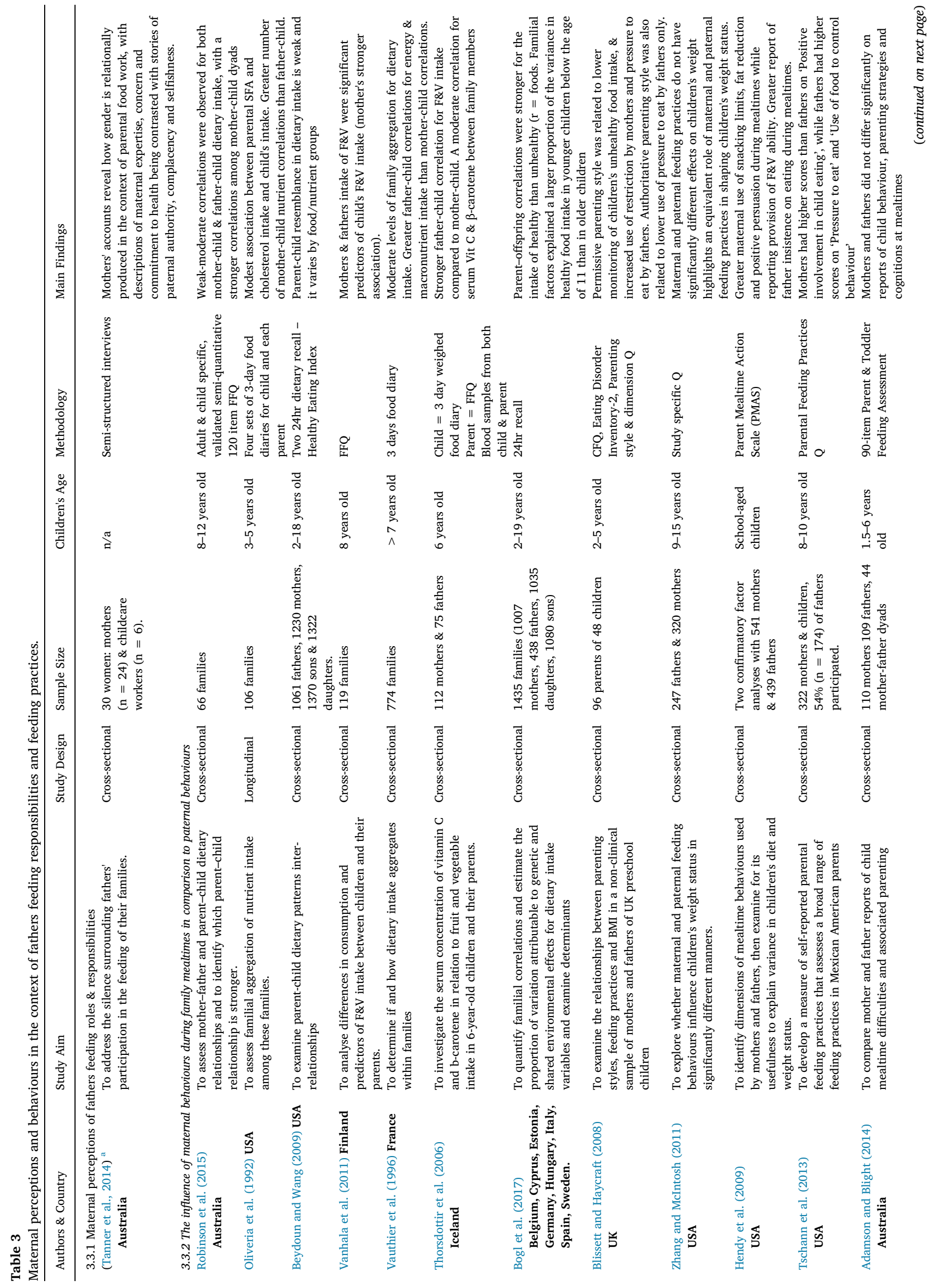


( $n=102$ ) of African-American fathers of children aged 3 to 13-yearsold and found that reported paternal modelling was not associated with child's intake of fruit, vegetables or sugar-sweetened beverages (Harris \& Ramsey, 2015). The study by Watterworth et al., (2017) that had a sample of 44 Canadian families with at least one preschool-age child, found that paternal modelling was associated with a lower children's nutrition risk score (Watterworth et al., 2017). However, comparisons cannot be generated between these studies, as the children's dietary outcome variables are different and the age ranges in each study are also not comparable.

Three qualitative studies to date have explored fathers' perceptions of role modelling and its importance (Fielding-Singh, 2017; Khandpur et al., 2016; Walsh et al., 2017). Fathers in the qualitative study by Walsh and colleagues believed they had a responsibility as the first role models to their child in terms of healthy eating behaviours. However, they feel that there was lack of information to guide them and that reliable information needs to be more accessible (Walsh et al., 2017). The majority of fathers in this study believed that there were ample opportunities to set an example and influence their children's eating behaviour, through both their words and actions around mealtimes (Walsh et al., 2017). Over 35\% of fathers in the qualitative study by Khandpur, Charles, et al. (2016) and Khandpur, and et al (2016) reported using role modelling to encourage their child aged 2 to 10 -yearsold to consume a balanced diet (Khandpur et al., 2016). Findings from the qualitative study by Fielding-Singh (2017) suggests that American fathers of adolescents felt that it was not their responsibility to cook or provide a healthy meal for their child; rather, for fathers, the drivethrough and processed foods were common solutions when faced with food-related tasks (Fielding-Singh, 2017). This lack of feeding responsibility in fathers of adolescents could be attributed to their child's age and their potential ability to prepare and cook meals on their own.

Overall, findings from studies suggest that fathers of younger children believe that role modelling is important to promote healthy eating behaviours, however, findings suggest that fathers need to be more aware of their behaviours around food as they can promote their child's intake of both healthy and unhealthy foods. Despite these findings, it is also necessary to examine the dietary intake between fathers and their child, because as previously stated paternal modelling can transfer eating behaviours from parent to child and is not always intentional (Vaughn et al., 2016).

\subsubsection{The association between father and child dietary intake}

Several studies to date have attempted to establish family resemblance in the dietary intake patterns, including both parents and at least one child. Findings from a systematic review and meta-analysis revealed that there are weak to moderate associations between parents and children's dietary intake (Wang et al., 2011). Although there has been no systematic review or meta-analysis conducted with studies containing fathers only, two longitudinal studies (Guerrero et al., 2016; Walsh et al., 2016), seven cross-sectional studies (Hall et al., 2011; Zuercher, Wagstaff, \& Kranz, 2011; Lloyd et al., 2014; Harris \& Ramsey, 2015; Vollmer, Adamsons, Gorin, et al., 2015; Walsh et al., 2015; Hebestreit et al., 2017), and one randomised-control trial (Williams et al., 2018) have investigated the potentially similarities between father's and their child's dietary intake. The two longitudinal studies have only investigated the influence of fathers' behaviours on pre-school aged children's dietary intake. The large American longitudinal study ( $n=2441$ ) by Guerrero et al., (2016) found that children had a lower odds ratio of consuming sugar-sweetened beverages (SSB) at 4 years of age if their fathers consumed breakfast more frequently with them when they were 2-years-old (Guerrero et al., 2016). Whereas, fathers who reported eating out more often with their child had children who were more likely to eat fast food and consume SSB (Guerrero et al., 2016). The other longitudinal study by Walsh et al. (2016) had a significantly smaller sample size of Australian fathers $(n=208)$, irrespective of this, findings suggested that fathers' intake of fruit and sweet 
snacks were positively associated with their child's intake of these foods between 20 months and 5 years of age (Walsh et al., 2016). In addition, a father's intake when the child was 20 months old was positively associated with a change in their child's sweet snack and SSB intake at both 3.5 and 5 years of age, along with an increase in their child's fruit intake at 3.5 years of age (Walsh et al., 2016).

The cross-sectional studies included had a low to large sample size ranging from 50 to 566 fathers, with two studies focusing on preschoolaged children (Vollmer, Adamsons, Gorin, et al., 2015; Walsh et al., 2015), two on primary school-aged children (Hall et al., 2011; Lloyd et al., 2014), two on both age groups (Harris \& Ramsey, 2015; Zuercher et al., 2011) and one study in children aged six to sixteen years old (Hebestreit et al., 2017). The studies were conducted in primarily Australian (Hall et al., 2011; Lloyd et al., 2014; Walsh et al., 2015) or American (Zuercher et al., 2011; Harris \& Ramsey, 2015; Vollmer, Adamsons, Gorin, et al., 2015) samples of fathers, with one study conducted in a European sample of fathers (Hebestreit et al., 2017). Findings from cross-sectional studies revealed that fathers' intake of fruit (Hall et al., 2011; Zuercher et al., 2011; Harris \& Ramsey, 2015; Vollmer, Adamsons, Gorin, et al., 2015; Walsh et al., 2015) and vegetables (Zuercher et al., 2011; Harris \& Ramsey, 2015; Vollmer, Adamsons, Gorin, et al., 2015; Walsh et al., 2015) were moderately to strongly positively associated with their child's intake of these food groups, with both positive (Hall et al., 2011; Walsh et al., 2015) and inverse (Harris \& Ramsey, 2015) associations observed with a child's and fathers' intakes of energy-dense foods.

Alternative methods to identify family resemblance have been conducted in cross-sectional studies in recent years to look beyond food group resemblance and take into consideration energy consumption (Lloyd et al., 2014), nutritional adequacy (Zuercher et al., 2011), and dietary patterns (Hebestreit et al., 2017). Lloyd et al. (2014) found a significant bivariate association between paternal and child percentage energy from core foods (i.e. foods providing essential nutrients for health) (Lloyd et al., 2014). The study by Zuercher et al. (2011) found significant correlations between fathers' and children's nutrient intake and if a father's intake was on course to meet their recommended nutrient intake, this doubled the odds for their child's diets to also meet recommendations (Zuercher et al., 2011). Finally, in terms of dietary patterns a large $(n=566)$ cross-sectional European study found that children's "Sweet \& Fat" dietary pattern was associated with fathers' "Sweet \& Fat" dietary patterns when they shared at least one meal a day with them (Hebestreit et al., 2017). In addition, the same dietary pattern correlation was evident between children and their fathers when soft drinks were available in the home (Hebestreit et al., 2017). The RCT called Healthy Dads, Healthy Kids was implemented in Southern Australian in 93 overweight or obese fathers with primary school-aged children to help fathers achieve their weight loss goals and educate them on how to be a role model of positive health behaviours for their children (Williams et al., 2018). Findings from 3 months post-RCT suggest that there was significant correlations between changes in fathers' and their child's intakes of carbohydrates, fruits, vegetarian sources of protein and the frequency of meals eaten with vegetables (Williams et al., 2018).

It should be noted that when evaluating these type of studies, it is important to take into consideration the reporter-bias of the child's dietary intake. Findings from a recent study revealed that there were significant parent-respondent interactions, such that there was a stronger parent-child association with the diet of parent reporting child's intake than the other parent (Vepsäläinen et al., 2018). In relation to the seven studies discussed, it is difficult to determine if reporter-bias influences these observed findings; as the child's intake was reported by mothers in three studies (both studies by Walsh and colleagues use the same sample cohort) (Hall et al., 2011; Walsh et al., 2015; Williams et al., 2018), by fathers in two studies (Harris \& Ramsey, 2015; Vollmer, Adamsons, Gorin, et al., 2015), unclear in three studies (Guerrero et al., 2016; Hebestreit et al., 2017; Lloyd et al.,
2014), and one study also unclear for younger children ( $<6$ years old) but self-reported by older children (Zuercher et al., 2011).

Overall, current research illustrates the positive and negative influence of paternal intake on child's food preference and subsequent food intake. Future studies should promote children's self-reported dietary intake (in children $\geq 8$ years old (Burrows et al., 2013)) or use more advanced methods of dietary assessment (e.g. biochemical sample analysis) to eliminate reporter's bias. All of the longitudinal studies reported in this review were in younger children $(<5$-years-old) and therefore it is difficult to determine if observed father-child correlations track into later childhood when the child becomes more autonomous and is subjected to numerous social and environmental factors. In addition, more research is required to determine the potential mechanisms that explain the associations between parent and a child's dietary intakes.

Family mealtimes also allow fathers to enforce rules around food and to encourage children to consume their dinner through paternal feeding practices. Therefore, it is important to establish the association between paternal feeding practices and children's eating behaviours and dietary intake.

\subsubsection{Paternal feeding practices}

Parenting practices relate to the behaviours or actions of parents for child-rearing purposes that may impact their child's beliefs, behaviours, and attitudes (Vaughn et al., 2016). Parenting behaviours can be domain-specific and parenting practices can vary based on the context in which they are used and therefore should be assessed individually i.e. parental feeding practices (Vaughn et al., 2016). Within the last two decades, there has been an increase in the quantity of research on paternal feeding practices and their association with various child outcomes. To understand these associations, the child and paternal characteristics must be taken into consideration first.

3.2.3.1. Paternal feeding practices in relation to child and paternal characteristics. Most of the studies exploring this association are primarily cross-sectional quantitative studies, except for one longitudinal study (Matton et al., 2013). Four studies found no differences in paternal feeding practices based on child's gender (Blissett et al., 2006; E. L.; Haycraft \& Blissett, 2008a; Payne, Galloway, \& Webb, 2011; Haycraft \& Blissett, 2012), with three studies illustrating that fathers reported more pressure to eat with their sons than their daughters (Loth et al., 2013; Orrell-Valente et al., 2007; Pulley et al., 2014). Findings from the longitudinal study suggest that more paternal monitoring led a reduction in overeating in only boys over the 6 month follow-up period, with these results marginally significant (Matton et al., 2013). In terms of a child's age, fathers of older children reported more feeding responsibilities (Kimberley $\mathrm{M}$ Mallan et al., 2014a,b) and restriction if concerned about their child's weight (Musher-Eizenman et al., 2009; Payne et al., 2011) than fathers of younger children. However, two studies found no association between a child's age and paternal controlling feeding practices (Blissett et al., 2006; Haycraft \& Blissett, 2012). The review by Khandpur et al., (2014) stated that there are inconsistent findings in terms of a child's gender and that fathers report using food to regulate emotions in younger children more so than older children (Khandpur et al., 2014). Therefore, more longitudinal research is required to establish how the temporality and stability of paternal feeding practices change as children get older.

In terms of paternal characteristics, five studies in the review by Khandpur et al. (2014) focused on paternal weight status or father's perception of his weight status (Khandpur et al., 2014). Findings from these studies suggest that higher body dissatisfaction was associated with higher paternal reports of monitoring with their sons (Blissett et al., 2006) and higher reports of pressure to eat with both their sons and daughters (Blissett \& Haycraft, 2011). Only one cross-sectional observational study to date has shown an association between fathers 
self-reported BMI and paternal use of pressure to eat during feeding (E. L. Haycraft \& Blissett, 2008b), with three other cross-sectional studies finding no associations (Blissett et al., 2006; Mallan et al., 2014a,b; Musher-Eizenman et al., 2009; Kimberley M). Only two quantitative cross-sectional studies have examined a possible association between paternal socio-economic status (SES) and paternal feeding practices, with one study suggesting that fathers from lower SES use more pressure to eat with their children (Kimberley M Mallan et al., 2014a,b), while the study found no significant associations between SES and paternal controlling feeding practices (Haycraft \& Blissett, 2012). A qualitative study by Khandpur and colleagues have also explored the influence of fathers' education level and residency status on paternal feeding practices (Khandpur et al., 2016). Twenty individual feeding practices were identified within this sample of American fathers, with fathers with higher education levels reporting more feeding on schedule $(75 \%$ vs. $50 \%)$, modelling eating practices ( $50 \%$ vs. $29 \%$ ) and using a distraction to feed ( $37 \%$ vs. $4 \%$ ) than fathers with lower education levels (Khandpur et al., 2016). Whereas fathers with lower education levels reported higher levels of letting their child dictate food preferences (92\% vs. 37\%) and using food to bond with their children ( $29 \%$ vs. $6 \%$ ) than fathers with higher education levels (Khandpur et al., 2016).

3.2.3.2. Paternal feeding practices and children's eating behaviours. Limited research has been conducted to establish the association between paternal feeding practices and children's eating behaviours, with the majority of research conducted in mother-child dyads. However, there have been four cross-sectional quantitative studies (Haycraft \& Blissett, 2012; Vollmer, Adamsons, Foster, et al., 2015a; Powell et al., 2017; Harris et al., 2018b) and one longitudinal (Matton et al., 2013) quantitative study conducted to explore this research question. The four cross-sectional studies included fathers of preschool children (Haycraft \& Blissett, 2012; Vollmer, Adamsons, Foster, et al., 2015a; Powell et al., 2017; Harris et al., 2018b) and the longitudinal study included fathers of school-aged children (Matton et al., 2013). Studies suggest that paternal reports of restriction and pressure to eat are associated with higher levels of avoidant eating (Haycraft \& Blissett, 2012; Vollmer, Adamsons, Foster, et al., 2015a; Harris et al., 2018b) and decreased ability of the child to self-regulate in the context of eating (Powell et al., 2017). In contrast Vollmer and colleagues found that paternal restriction was associated with higher food approach eating behaviours and pressure to eat was associated with lower food approach eating behaviours (Vollmer, Adamsons, Foster, et al., 2015a). Finally, as previously mentioned, Matton et al., (2014) found that more paternal monitoring led a reduction in overeating in only boys over a 6 month follow-up period (Matton et al., 2013), with Haycraft \& Blissett finding that higher paternal monitoring was associated with decreased emotional under-eating in all children (Haycraft \& Blissett, 2012). No qualitative studies to date have explicitly investigated fathers' behaviours around mealtimes in relation to their child's eating behaviours. Therefore, more research is required to understand fathers' attitudes and beliefs in relation to their child's eating behaviours, such as how they respond to them, while longitudinal studies would allow us to examine the direction of the relationship.

3.2.3.3. Paternal feeding practices and child's dietary intake. Following on from this, we need to establish direct associations between paternal feeding practices and child's dietary intake. As illustrated by the systematic review and meta-analysis by Yee et al., (2017) there is a large body of research investigating the association between parental feeding practices and their child's 'healthy' and 'unhealthy' dietary intake. However, unfortunately, the majority of studies do not include fathers at all or if fathers are included in the study, they only represent a small proportion of the sample and the results report mothers and fathers collectively (Yee et al., 2017). To date, only three cross-sectional studies directly explored the association between paternal feeding practices and a measure of their preschool child's dietary intake (Vollmer, Adamsons, Gorin, et al., 2015; Lora et al., 2016; Watterworth et al., 2017). Vollmer and colleagues found no significant association between paternal feeding practices and their child's dietary quality score (Vollmer, Adamsons, Gorin, et al., 2015). The study by Watterworth and colleagues used a child's nutrition risk score as an outcome measure of the child's dietary intake and found that a father's use of coercive feeding practices were associated with a higher children's nutrition risk score (Watterworth et al., 2017). With fathers' reports of role modelling, involving children in meal preparation and providing a healthy home, associated with a reduced children's nutritional risk score in preschool Canadian children (Watterworth et al., 2017). The cross-sectional study by Lora et al., (2016) found that paternal use of food as a reward or to calm the child was associated with increased SSB intake in Hispanic but not African American preschool children (Lora et al., 2016). Therefore, no clear conclusion can be made given the range of outcome variables used to assess children's dietary intakes. While the potential long-term influence needs to establish by recruiting a sample of older children or ideally conducting longitudinal studies.

It should also be noted that two longitudinal studies have explored associations between parenting styles and their child's food intake, with parenting styles representing the emotional condition of the parentchild relationship (Alsharairi \& Somerset, 2015). The study by Alsharairi and Somerset (2015) found that fathers, who reported a permissive parenting style when child was aged 4 to 5-years-old, had children with higher odds of consuming $>1$ portion of fruit and vegetable two years later, compared to fathers who reported a disengaged parenting style (Alsharairi \& Somerset, 2015). While fathers who reported an authoritative parenting style when child was aged 4 to 5years-old, had children with higher odds of consuming $>1$ portion of fruit and vegetable two years later (in girls only) and four years later (in boys only), compared to fathers who reported a disengaged parenting style (Alsharairi \& Somerset, 2015). The longitudinal study by Berge and colleagues in American adolescents found that paternal permissive feeding style predicted their daughter's fruit and vegetable intake five years later when compared to authoritarian fathers (Berge et al., 2010). More research is required to establish how the emotional climate in relation to feeding can influence paternal feedings practices and children's dietary intake.

Overall, findings suggest that fathers play an important role in the development of eating behaviours. The context and type of paternal behaviour around mealtimes can determine whether paternal presence and influence will have a positive or negative influence on a child's eating behaviours and dietary intake. However, as research predominately focuses on mothers in relation to child feeding, this review needs to address maternal perceptions of fathers feeding responsibilities and explore the differences in maternal and paternal behaviours during family mealtimes.

\subsection{Maternal perceptions and behaviours in the context of paternal feeding responsibilities and feeding practices}

Mothers are predominately the primary caregiver and according to Townsend are referred to as the 'default parent' (Townsend, 2002). This statement is supported by most studies and interventions that include children as they primarily include mothers as the primary care-giver (Davison et al., 2018; Morgan et al., 2017). As research suggests that mothers are more responsible for feeding their children than fathers, it is necessary to understand their perceptions in relation to their partners' involvement in feeding their child as this may give insight to the factors influencing the roles and responsibilities of fathers (Blissett et al., 2006; Ek et al., 2016; Harris et al., 2018a; Pulley et al., 2014). In addition, children's dietary intake can be influenced by their mothers' and fathers' attitudes and behaviours, and therefore the associations between 
mothers' and fathers' behaviours during mealtimes need to be examined collectively to determine if similarities or differences exist.

\subsubsection{Maternal perceptions of fathers feeding roles \& responsibilities}

To establish how mothers perceive fathers' role in feeding, we need to determine how mothers view their responsibilities in comparison to fathers. Two qualitative studies addressed this question in mothers of preschool children (Tanner, Petersen, \& Fraser, 2014) and adolescents (Fielding-Singh, 2017). Findings from Tanner and colleagues suggest that all the women ( $\mathrm{n}=24$ mothers, $\mathrm{n}=6$ social care providers) participating in the study viewed themselves the primary, or in some cases the only person responsible for managing their family's diet (Tanner et al., 2014). Women in this study said fathers lack of cooking skills were the most common reason for fathers not preparing or cooking meals, with many mothers believing they had to cook in order to provide 'fresh' and healthy family meals. However, the women interviewed were accepting of their partners lack of involvement, as although fathers were often willing to cook, mothers knew they were the superior cook and in addition had a greater interest in cooking than fathers (Tanner et al., 2014). The study by Fielding-Singh (2017) consisted of in-depth interviews of American middle- and upper-class families, with at least one parent and one adolescent interviewed (Fielding-Singh, 2017). Findings suggest that mothers were concerned about fathers detachment or disinterest in a healthy diet, with mothers worried about fathers modelling of unhealthy dietary behaviours to adolescents, and fathers feeding adolescents unhealthy foods (FieldingSingh, 2017). Mothers in this study did not see food-work or healthy eating as part of their partners' duties and only a few mothers thought that the unequitable division of labour around mealtimes was unjust (Fielding-Singh, 2017).

In terms of general paternal roles, studies have found that maternal perception of a father's responsibility as a carer for their child is a strong predictor of father involvement, regardless of a father's perception of his role (Grossman, Pollack, \& Golding, 1988; McBride et al., 2005; McBride \& Rane, 1997). Limited research within a feeding context has been conducted and therefore it is not fully understood how this psychological concept may influence paternal feeding practices. A quantitative study in American fathers $(n=150)$ somewhat investigated this concept, with a father's perception of his partner's views of both his role as a father in general and during mealtimes not differing from his own perceptions (Vollmer, Adamsons, Foster, et al., 2015b). These findings suggest that fathers believe that their partner identifies the father as an important figure within the family and during mealtimes. However, as stated by Vollmer and colleagues in the limitations of the study, it is difficult to determine if fathers reported their partner's perceptions of the role of the father accurately and ideally the father's partner should have completed this questionnaire (Vollmer, Adamsons, Foster, et al., 2015b).

It is necessary to explore parental perceptions of feeding roles, as they can influence parental behaviours during mealtimes and can be directly interpreted by children. Therefore, the similarities or differences between mothers and fathers behaviours during mealtimes need to be examined and subsequently how their behaviours are associated with their child's eating behaviours and dietary intake.

\subsubsection{The influence of maternal behaviours during family mealtimes in comparison to paternal behaviours}

There is some conflicting evidence within the literature in terms of which parent has the greatest influence on a child's diet, with some studies reporting greater mother-child correlations (Beydoun \& Wang, 2009; Oliveria et al., 1992; Robinson et al., 2015; Vanhala et al., 2011; Vepsäläinen et al., 2018) and others reporting greater father-child correlations (Thorsdottir et al., 2006; Vauthier et al., 1996) for food and nutrient intake. The studies that found greater mother-child dietary associations were generally more recent, and were larger cross-sectional studies with a larger age range (1-18 years old) (Beydoun \&
Wang, 2009; Bogl et al., 2017; Robinson et al., 2015; Vanhala et al., 2011; Vepsäläinen et al., 2018) compared to those who reported greater father-child correlations (Thorsdottir et al., 2006; Vauthier et al., 1996). However, in the majority of studies, it is unclear whether the mother or father reported their child's dietary intake, which may result in reporters-bias and parent-respondent interactions, such that there may be a stronger parent-child association with the diet of parent reporting the child's intake compared to the other parent (Vepsäläinen et al., 2018).

In terms of parental feeding practices findings from the comprehensive review by Khandpur et al. (2014) illustrate that nine out of twelve studies found significant differences between the meal-time feeding practices of mothers and fathers, which will be elaborated on below (Khandpur et al., 2014). The three studies that found no significant differences were cross-sectional in design and had small sample sizes (two had 23 fathers and one had 107 fathers) (E. L. Haycraft and Blissett, 2008b,a, Blissett \& Haycraft, 2011). Khandpur et al. (2014) suggest that in comparison to mothers, fathers reported lower levels of monitoring (Blissett \& Haycraft, 2008; Blissett et al., 2006) and frequency of meals with their child (Haycraft \& Blissett, 2012). Fathers were also less likely to monitor children's snack food intake (Zhang \& McIntosh, 2011), place limit on snack foods or ensure availability of fruit and vegetables (Hendy et al., 2009). In contrast, fathers had a higher level of control in the amount of food consumed by the child (Hendy et al., 2009), restrictive feeding practices (Musher-Eizenman et al., 2009) and greater use of pressure to eat (Hendy et al., 2009; Loth et al., 2013; Tschann et al., 2013) than mothers. While the observational study by Orrell-Valente et al., (2007) found that fathers were less likely to use neutral prompts, reasoning, or praise and used fewer feeding strategies in general per meal than mothers (Orrell-Valente et al., 2007).

The studies that have been conducted in the years after Khandpur and colleagues comprehensive review in 2014 also illustrate conflicting evidence between maternal and paternal feeding practices. The six cross-sectional quantitative studies are primarily in parents of preschool-aged children (Adamson \& Blight, 2014; Harris et al., 2018b; Jansen et al., 2018; Powell, Frankel, \& Hernandez, 2017; Pratt et al., 2017). Half of the studies conducted with both parents (Adamson \& Blight, 2014; Harris et al., 2018b; Jansen et al., 2018; Pulley et al., 2014) and half using the same measurement tool to assess parental feeding practices (Feeding Practices and Structure Questionnaire) (Harris et al., 2018b; Jansen et al., 2018; Powell, Frankel, et al., 2017). Out of the six studies, three were in Australian samples (Adamson \& Blight, 2014; Harris et al., 2018b; Jansen et al., 2018) and three were in American samples (Powell, Frankel, et al., 2017; Pratt et al., 2017; Pulley et al., 2014). One study found no significant difference between mothers and fathers and how they respond to mealtime issues (Adamson \& Blight, 2014). While another study assessed the parental feeding practices of 77 American families (children aged 6-12 years) and found that fathers reported greater pressure to eat with their children than mothers did, with no differences reported between mothers and fathers use of restrictive feeding practices (Pulley et al., 2014). Two studies conducted secondary analyses on the same study sample: Mums and Dads (MAD) for mealtimes (Harris et al., 2018b; Jansen et al., 2018). The study by Jansen and colleagues included all mothers $(\mathrm{n}=279)$ and fathers $(\mathrm{n}=335)$ from the $M A D$ for mealtimes study (Jansen et al., 2018), whereas Harris and colleagues only included mother-father pairs $(n=208)$ (Harris et al., 2018b). Both studies found that fathers endorsed using food as a reward for good behaviour more so than mothers (Harris et al., 2018b; Jansen et al., 2018), with no significant difference observed between mother and father reports of persuasive feeding and reward for eating (Harris et al., 2018b). In contrast, Jansen and colleagues found that fathers reported more reward for eating and less covert restriction and structured meal timing than mothers (Jansen et al., 2018). Differences may exist between studies due to the set of subjects selected within the sample. 
Similarly, Powell, and et al (2017) and Powell, Frankel, et al. (2017) found that fathers endorse using food as a reward for good behaviour more so than mothers (Powell, Frankel, et al., 2017), and Pratt et al. (2017) also found that fathers used more coercive food parenting strategies and less structure-based parenting strategies than mothers (Pratt et al., 2017).

Findings from two qualitative studies support those from quantitative studies (Khandpur, Charles, et al., 2016; Tanner et al., 2014). Tanner and colleagues suggest that mothers believe that fathers were 'tougher' or 'harder' with their children than they were and displayed a more authoritarian role in relation to feeding routines, especially when the father expressed concern over their child's weight (Tanner et al., 2014). Khandpur and colleagues conducted a study investigating fathers perceptions on feeding practices and responsibilities utilised by them and their partners (Khandpur, Charles, et al., 2016). Findings revealed that approximately half (46\%) of fathers reported cooperative food parenting practices with their partner, whereas $40 \%$ stated that there were conflicting food parenting practices. Fathers reported that conflict arose around access to energy-dense foods and introducing variety to the diet. Dissimilarities in practices were due to differences in parental eating habits and feeding philosophies as well as concern for their child's health/weight, which fathers reported often resulted in the child refusing to eat (Khandpur, Charles, et al., 2016).

Overall, it is clear that there are some differences between maternal and paternal feeding practices. In general, it appears that fathers utilise more coercive feeding practices, which suggests they adopt a more authoritarian figure during mealtimes than mothers. In addition, further research is required to establish both the individual and common predictors of maternal and paternal feeding practices.

\section{Conclusion}

The literature to date suggests that while mothers still view themselves as the primary caregiver, fathers have some form of responsibility in some aspect of feeding their child, from deciding food availability in the home (grocery shopping) to interacting with their child during mealtimes. However, as with research in mother-child dyads, the interactions during mealtimes between fathers and their children can both positively and negatively influence children's long-term eating behaviour. These interactions include the types of foods fathers choose to eat in the presence of their children, which can consequently encourage role modelling and influence children to adopt a similar eating patterns to their fathers if they frequently engage in mealtimes with one another. Another interaction during mealtimes and a recurrent theme in the literature is fathers' greater use of coercive feeding practices in comparison to mothers and its association with food avoidant eating behaviours in children. Overall, research to date highlights the importance of including fathers in research relating to children's dietary intakes. Studies to date that have touched on various aspects of fathers' attitude and behaviour in relation to child feeding and have significantly contributed to the literature. However, future research needs to investigate family meals as a broader construct and include children from infancy to adolescence. The entire family context needs to be taken into consideration, with both quantitative and qualitative studies necessary to gain a fuller understanding of the differential influence on children's dietary intake from the numerous individuals involved in the child's daily routine.

\section{Financial support}

This work was supported by the Department of Agriculture Food and Marine, under the National Development Plan 2000-2006. Department of Agriculture Food and Marine had no role in the design, analysis or writing of this article.

\section{Authorship}

S. Rahill was involved in compiling the relevant articles and writing the narrative review. A. Kennedy and J. Kearney were responsible for reviewing article.

\section{Declaration of competing interest}

None.

\section{Appendix A. Supplementary data}

Supplementary data to this article can be found online at https:// doi.org/10.1016/j.appet.2019.104540.

\section{References}

eurostat (2017). People in the EU - statistics on household and family structures - statistics Explained. Available at: https://ec.europa.eu/eurostat/statistics-explained/index. php?title=People_in_the_EU_-_statistics_on_household_and_family_structures\#Singleperson households: differences between EU Member States, Accessed date: 4 December 2018.

Adamson, M., \& Blight, E. J. (2014). Bringing dads to the table: Comparing mother and father reports of child behaviour and parenting at mealtimes. Journal of Family Studies. Routledge, 20(2), 118-127. https://doi.org/10.1080/13229400.2014. 11082001.

Alsharairi, N. A., \& Somerset, S. M. (2015). 'Associations between parenting styles and children's fruit and vegetable intake', Ecology of Food and nutrition. Routledge, 54(1), 93-113. https://doi.org/10.1080/03670244.2014.953248.

Bandura, A. (1977). Self-efficacy: Toward a unifying theory of behavioral change. Psychological Review, 84(2), 191-215. https://doi.org/10.1037/0033-295X.84.2.191.

Bennett, A. E., McCartney, D., \& Kearney, J. M. (2016). midwifery. Views of fathers in Ireland on the experience and challenges of having a breast-feeding partner, Vol 40Elsevierhttps://doi.org/10.1016/j.midw.2016.07.004.

Berge, J. M., et al. (2010). Parenting style as a predictor of adolescent weight and weight related behaviors. Journal of Adolescent Health, 46(4), 331-338. https://doi.org/10. 1016/j.jadohealth.2009.08.004.

Beydoun, M. A., \& Wang, Y. (2009). Parent-child dietary intake resemblance in the United States: Evidence from a large representative survey. Social Science \& Medicine. Pergamon, 68(12), 2137-2144. https://doi.org/10.1016/J.SOCSCIMED.2009.03.029.

Bianchi, S. M. (2000). Maternal employment and time with children: Dramatic change or surprising continuity? Demography. Springer-Verlag, 37(4), 401-414. https://doi.org/ 10.1353/dem.2000.0001.

Blissett, J., \& Haycraft, E. (2008). Are parenting style and controlling feeding practices related? Appetite, 50(2-3), 477-485. https://doi.org/10.1016/j.appet.2007.10.003.

Blissett, J., \& Haycraft, E. (2011). Parental eating disorder symptoms and observations of mealtime interactions with children. Journal of Psychosomatic Research, 70(4), 368-371. https://doi.org/10.1016/J.JPSYCHORES.2010.07.006 Elsevier.

Blissett, J., Meyer, C., \& Haycraft, E. (2006). Maternal and paternal controlling feeding practices with male and female children. Appetite, 47(2), 212-219. https://doi.org/ 10.1016/j.appet.2006.04.002

Bogl, L., et al. (2017). Familial resemblance in dietary intakes of children, adolescents, and parents: Does dietary quality play a role? Nutrients, 9(8), 892. https://doi.org/10 3390/nu9080892.

Brown, A., \& Davies, R. (2014). Fathers' experiences of supporting breastfeeding: Challenges for breastfeeding promotion and education. Maternal \& child nutrition. Wiley-Blackwell, 10(4), 510-526. https://doi.org/10.1111/mcn.12129.

Brown, R., \& Ogden, J. (2004). Children's eating attitudes and behaviour: A study of the modelling and control theories of parental influence. Health Education Research, 19(3), 261-271. https://doi.org/10.1093/her/cyg040.

Burrows, T. L., et al. (2013). A comparison and validation of child versus parent reporting of children's energy intake using food frequency questionnaires versus food records: Who's an accurate reporter? Clinical Nutrition, 32(4), 613-618. https://doi.org/10. 1016/j.clnu.2012.11.006.

Cooke, L. J., et al. (2004). Demographic, familial and trait predictors of fruit and vegetable consumption by pre-school children. Public Health Nutrition, 7(02), 295-302. https://doi.org/10.1079/PHN2003527.

Daniels, L. A., et al. (2013). Outcomes of an early feeding practices intervention to prevent childhood obesity. Pediatrics, 132(1), e109-e118. https://doi.org/10.1542/peds. 2012-2882.

Davison, K. K., et al. (2018). The forgotten parent: Fathers' representation in family interventions to prevent childhood obesity. Preventive Medicine, 111, 170-176. https:// doi.org/10.1016/j.ypmed.2018.02.029.

Doherty, W. J., Kouneski, E. F., \& Erickson, M. F. (1998). Responsible fathering: An overview and conceptual framework. Journal of Marriage and the Family. National Council on Family Relations, 60(2), 277. https://doi.org/10.2307/353848.

Ek, A., et al. (2016). Associations between parental concerns about preschoolers' weight and eating and parental feeding practices: Results from analyses of the child eating behavior questionnaire, the child feeding questionnaire, and the lifestyle behavior checklist. PLoS One, 11(1), e0147257. https://doi.org/10.1371/journal.pone. 
0147257 Edited by Y.-C. Chen. Public Library of Science.

Feinberg, M. E. (2003). 'The internal structure and ecological context of coparenting: A framework for research and intervention.', parenting, science and practice. NIH Public Access, 3(2), 95-131. https://doi.org/10.1207/S15327922PAR0302_01.

Fielding-Singh, P. (2017). Dining with dad: Fathers' influences on family food practices, Vol 117, Appetite. Academic Press98-108. https://doi.org/10.1016/J.APPET.2017.06. 013.

Goldman, R. L., Radnitz, C. L., \& McGrath, R. E. (2012). The role of family variables in fruit and vegetable consumption in preschool children. Journal of Public Health Research, 1(2), 22. https://doi.org/10.4081/jphr.2012.e22.

Grossman, F., Pollack, W., \& Golding, E. (1988). Fathers and children: Predicting the quality and quantity of fathering. Developmental Psychology, 24, 82-91.

Guerrero, A. D., et al. (2016). Father involvement in feeding interactions with their young children. American journal of health behavior. NIH Public Access, 40(2), 221-230. https://doi.org/10.5993/AJHB.40.2.7.

Hall, L., et al. (2011). Children's intake of fruit and selected energy-dense nutrient-poor foods is associated with fathers' intake. Journal of the American Dietetic Association, 111(7), 1039-1044. https://doi.org/10.1016/j.jada.2011.04.008.

Hansen, E., Tesch, L., \& Ayton, J. (2018). They're born to get breastfed'- how fathers view breastfeeding: A mixed method study. BMC Pregnancy and Childbirth. BioMed Central, 18(1), 238. https://doi.org/10.1186/s12884-018-1827-9.

Harris, H. A., et al. (2018a). Concern explaining nonresponsive feeding: A study of mothers' and fathers' response to their child's fussy eating. Journal of Nutrition Education and Behavior. Elsevier Inc. 50(8), 757-764. https://doi.org/10.1016/j.jneb.2018.05. 021.

Harris, H. A., et al. (2018b). Do dads make a difference? Family feeding dynamics and child fussy eating. Journal of Developmental and Behavioral Pediatrics, 39(5), 415-423. https://doi.org/10.1097/DBP.0000000000000566.

Harris, T. S., \& Ramsey, M. (2015). Paternal modeling, household availability, and paternal intake as predictors of fruit, vegetable, and sweetened beverage consumption among African American children, Vol 85, Appetite. Academic Press171-177. https://doi.org/ 10.1016/J.APPET.2014.11.008.

Haycraft, E. L., \& Blissett, J. M. (2008a). Controlling feeding practices and psychopathology in a non-clinical sample of mothers and fathers. Eating Behaviors. Pergamon, 9(4), 484-492. https://doi.org/10.1016/J.EATBEH.2008.07.007.

Haycraft, E. L., \& Blissett, J. M. (2008b). Maternal and paternal controlling feeding practices: Reliability and relationships with BMI. Obesity, 16(7), 1552-1558. https:// doi.org/10.1038/oby.2008.238.

Haycraft, E., \& Blissett, J. (2012). Predictors of paternal and maternal controlling feeding practices with 2- to 5-year-old children. Journal of Nutrition Education and Behavior 44(5), 390-397. https://doi.org/10.1016/j.jneb.2010.03.001.

Hebestreit, A., et al. (2017). Dietary patterns of European children and their parents in association with family food environment: Results from the I.family study. Nutrients. Multidisciplinary Digital Publishing Institute (MDPI), 9(2), 126. https://doi.org/10. 3390/nu9020126.

Hendy, H. M., et al. (2009). The Parent Mealtime Action Scale (PMAS). Development and association with children's diet and weight. Appetite, 52(2), 328-339. https://doi.org/ 10.1016/j.appet.2008.11.003.

Herman, C., \& Polivy, J. (2005). Normative influences on food intake. Physiology \& Behavior, 86(5), 762-772. https://doi.org/10.1016/j.physbeh.2005.08.064.

Horodynski, M., \& Arndt, M. J. (2005). "Eating-together" mealtimes with AfricanAmerican fathers and their toddlers. Applied Nursing Research : ANR. W.B. Saunders Ltd, 18(2), 106-109. https://doi.org/10.1016/j.apnr.2004.05.002.

Jansen, E., et al. (2018). Measurement invariance of the Feeding Practices and Structure Questionnaire-28 among a community of socioeconomically disadvantaged mothers and fathers. Appetite, 120, 115-122. https://doi.org/10.1016/j.appet.2017.08.030.

Kenosi, M., et al. (2011). Are fathers underused advocates for breastfeeding? Irish Medical Journal, 104(10), 313-315. Available at: http://www.ncbi.nlm.nih.gov/pubmed/ 22256447, Accessed date: 7 November 2018.

Khandpur, N., Charles, J., \& Davison, K. K. (2016). Fathers' perspectives on coparenting in the context of child feeding. Childhood Obesity, 12(6), 455-462. https://doi.org/10 1089/chi.2016.0118.

Khandpur, N., et al. (2014). Fathers' child feeding practices: A review of the evidence. Appetite, 78, 110-121. https://doi.org/10.1016/j.appet.2014.03.015.

Khandpur, N., et al. (2016). Diversity in fathers' food parenting practices : A qualitative exploration within a heterogeneous sample, Vol 101, Appetite. Elsevier Ltd134-145. https://doi.org/10.1016/j.appet.2016.02.161.

Larsen, J. K., Hermans, R. C. J., et al. (2015). How parental dietary behavior and food parenting practices affect children's dietary behavior. Interacting sources of influence? Appetite, 89, 246-257. https://doi.org/10.1016/j.appet.2015.02.012.

Lloyd, A. B., et al. (2014). Maternal and paternal parenting practices and their influence on children's adiposity, screen-time, diet and physical activity, Vol 79, Appetite. Elsevier Ltd149-157. https://doi.org/10.1016/j.appet.2014.04.010.

Lora, K. R., et al. (2016). African-American and Hispanic children's beverage intake: Differences in associations with desire to drink, fathers' feeding practices, and weight concerns. Appetite. NIH Public Access, 107, 558-567. https://doi.org/10.1016/j.appet. 2016.09.012.

Loth, K. A., et al. (2013). 'Food-related parenting practices and adolescent weight status: A population-based study. Pediatrics. American Academy of Pediatrics, 131(5), e1443-e1450. https://doi.org/10.1542/peds.2012-3073.

Mallan, K. M., et al. (2014a). Dads at the dinner table. A cross-sectional study of Australian fathers' child feeding perceptions and practices. Appetite, 73, 40-44 Available at: http://www.ncbi.nlm.nih.gov/pubmed/24511617, Accessed date: 22 June 2018.

Mallan, K. M., et al. (2014b). The role of fathers in child feeding: Perceived responsibility and predictors of participation. Child Care, Health and Development. Wiley/Blackwell,
40(5), 715-722. https://doi.org/10.1111/cch.12088 10.1111.

Matton, A., et al. (2013). Continuity in primary school children's eating problems and the influence of parental feeding strategies. Journal of Youth and Adolescence. Springer US, 42(1), 52-66. https://doi.org/10.1007/s10964-012-9794-3.

May, C., Chai, L. K., \& Burrows, T. (2017). Parent, partner, co-parent or partnership? The need for clarity as family systems thinking takes hold in the quest to motivate behavioural change. Children (Basel, Switzerland). Multidisciplinary Digital Publishing Institute (MDPI), 4(4), 29. https://doi.org/10.3390/children4040029.

McBride, B., et al. (2005). Parental identity, maternal gatekeeping, and father involvement. Family Relations, 54, 360-372.

McBride, B. A., \& Rane, T. R. (1997). Role identity, role investments, and paternal involvement: Implications for parenting programs for men. Early Childhood Research Quarterly, 12, 173-197.

Minuchin, P. (1985). 'Families and individual development: Provocations from the field of family therapy. Child Development. WileySociety for Research in Child Development, 56(2), 289. https://doi.org/10.2307/1129720.

Morgan, P. J., et al. (2017). Involvement of fathers in pediatric obesity treatment and prevention trials: A systematic review. Pediatrics. American Academy of Pediatrics, 139(2), https://doi.org/10.1542/peds.2016-2635.

Murdock, G. (1949). Social structure (2nd ed.). MacMillan Company.

Musher-Eizenman, D. R., et al. (2009). Child and parent characteristics related to parental feeding practices. A cross-cultural examination in the US and France. Appetite, 52(1), 89-95. https://doi.org/10.1016/j.appet.2008.08.007.

Oliveria, S. A., et al. (1992). Parent-child relationships in nutrient intake: The framingham children's study. The American Journal of Clinical Nutrition. Oxford University Press, 56(3), 593-598. https://doi.org/10.1093/ajcn/56.3.593.

Orrell-Valente, J. K., et al. (2007). "Just three more bites": An observational analysis of parents' socialization of children's eating at mealtime. Appetite. Academic Press, 48(1), 37-45. https://doi.org/10.1016/J.APPET.2006.06.006.

Parke, R. D. (2008). Father involvement. Marriage \& Family Review. Taylor \& Francis Group, 29(2-3), 43-58. https://doi.org/10.1300/J002v29n02_04.

Payne, L. O., Galloway, A. T., \& Webb, R. M. (2011). Parental use of differential restrictive feeding practices with siblings. International Journal of Pediatric Obesity, 6(2-2), e540-e546. https://doi.org/10.3109/17477166.2011.575144.

Pleck, J., \& Masciadrelli, B. (2004). Paternal involvement by U.S. Residential fathers: Levels, sources, and consequences. The role of the father in child developement (pp. 222-271). (4th ed.). New York: Wiley.

Powell, E. M., et al. (2017). The relationship between adult attachment orientation and child self-regulation in eating: The mediating role of persuasive-controlling feeding practices. Eating Behaviors, 26, 121-128. https://doi.org/10.1016/j.eatbeh.2017.02. 006.

Powell, E. M., Frankel, L. A., \& Hernandez, D. (2017). The mediating role of child selfregulation of eating in the relationship between parental use of food as a reward and child emotional overeating, Vol 113, Appetite. Elsevier Ltd78-83. https://doi.org/10.1016/j. appet.2017.02.017.

Pratt, M., et al. (2017). 'Structure, coercive control, and autonomy promotion: A comparison of fathers' and mothers' food parenting strategies. Journal of Health Psychology. SAGE PublicationsSage UK: London, England. https://doi.org/10.1177/ 1359105317707257135910531770725

Pulley, C., et al. (2014). Parental child feeding practices: How do perceptions of mother, father, sibling, and self vary? Appetite, 80, 96-102. https://doi.org/10.1016/j.appet. 2014.05.001.

Reinaerts, E., et al. (2007). Explaining school children's fruit and vegetable consumption: The contributions of availability, accessibility, exposure, parental consumption and habit in addition to psychosocial factors. Appetite. Academic Press, 48(2), 248-258. https://doi.org/10.1016/J.APPET.2006.09.007.

Rempel, L. A., \& Rempel, J. K. (2011). The breastfeeding team: The role of involved fathers in the breastfeeding family. Journal of Human Lactation. SAGE PublicationsSage CA: Los Angeles, CA, 27(2), 115-121. https://doi.org/10.1177/0890334410390045.

Robinson, L. N., et al. (2015). Relationships between dietary intakes of children and their parents: A cross-sectional, secondary analysis of families participating in the family diet quality study. Journal of Human Nutrition and Dietetics. Wiley/Blackwell, 28(5), 443-451. https://doi.org/10.1111/jhn.12261 10.1111.

Spinney, L. (2011). Venus and mars collide. New Science, 43-45 209.

Tamis-Lemonda, C. S., \& Cabrera, N. (1999). Perspectives on father involvement: Research and policy. Social Policy Report Society for Research in Child Development, 13(2), 1-25. Available at: http://srcd.org/sites/default/files/documents/spr13-2. pdf, Accessed date: 26 November 2018.

Tanner, C., Petersen, A., \& Fraser, S. (2014). Food, fat and family: Thinking fathers through mothers' words. Women's Studies International Forum. Pergamon, 44, 209-219. https://doi.org/10.1016/J.WSIF.2013.01.017.

Thorsdottir, I., et al. (2006). Fruit and vegetable intake: vitamin C and beta-carotene intake and serum concentrations in six-year-old children and their parents. Food \& Nutrition Research, 50(2), 71-76. https://doi.org/10.3402/fnr.v50i2.1561.

Townsend, N. W. (2002). The package deal : Marriage, work, and fatherhood in men's lives. Temple University Press. Available at: https://books.google.ie/books/about/ Package_Deal.html?id =Fl-GEzEvHVkC\&redir_esc =y, Accessed date: 28 November 2018 .

Tschann, J. M., et al. (2013). Parental feeding practices in Mexican American families: Initial test of an expanded measure. International Journal of Behavioral Nutrition and Physical Activity. BioMed Central, 10(1), 6. https://doi.org/10.1186/1479-5868-10-6.

Vanhala, M. L., et al. (2011). Parental predictors of fruit and vegetable consumption in treatment-seeking overweight children. Journal of Human Nutrition and Dietetics, 24(1), 47-53. https://doi.org/10.1111/j.1365-277X.2010.01133.x.

Vaughn, A. E., et al. (2016). Fundamental constructs in food parenting practices: A content map to guide future research. Nutrition Reviews. Oxford University Press, 74(2), 
98-117. https://doi.org/10.1093/nutrit/nuv061.

Vauthier, J. M., et al. (1996). Family resemblance in energy and macronutrient intakes: The stanislas family study. International Journal of Epidemiology, 25(5), 1030-1037. Available at: http://www.ncbi.nlm.nih.gov/pubmed/8921491, Accessed date: 20 November 2018.

Vepsäläinen, H., et al. (2018). Like parent, like child? Dietary resemblance in families. International Journal of Behavioral Nutrition and Physical Activity. BioMed Central, 15(1), 62. https://doi.org/10.1186/s12966-018-0693-1.

Vollmer, R. L., Adamsons, K., Foster, J. S., et al. (2015a). Association of fathers' feeding practices and feeding style on preschool age children's diet quality, eating behavior and body mass index. Appetite, 89, 274-281. https://doi.org/10.1016/j.appet.2015. 02.021 .

Vollmer, R. L., Adamsons, K., Foster, J. S., et al. (2015b). Investigating relationships between paternal perception of the role of the father and paternal feeding practices. Journal of Child and Family Studies. Springer US, 24(12), 3734-3741. https://doi.org/ 10.1007/s10826-015-0181-z.

Vollmer, R. L., Adamsons, K., Gorin, A., et al. (2015). Investigating the relationship of body mass index, diet quality, and physical activity level between fathers and their preschool-aged children. Journal of the Academy of Nutrition and Dietetics, 115(6), 919-926. https://doi.org/10.1016/J.JAND.2014.12.003 Elsevier.

Walsh, A. D., et al. (2015). Associations between dietary intakes of first-time fathers and their 20-month-old children are moderated by fathers' BMI, education and age. British Journal of Nutrition. Cambridge University Press, 114(06), 988-994. https://doi.org/ 10.1017/S0007114515002755.

Walsh, A. D., et al. (2016). Dietary associations of fathers and their children between the ages of 20 months and 5 years. Public Health Nutrition. Cambridge University Press, 19(11), 2033-2039. https://doi.org/10.1017/S136898001600077X.

Walsh, A. D., et al. (2017). Fathers' perspectives on the diets and physical activity behaviours of their young children. PloS one. Public Library of Science, 12(6), e0179210. https://doi.org/10.1371/journal.pone.0179210.

Wang, Y., et al. (2011). Do children and their parents eat a similar diet? Resemblance in child and parental dietary intake: Systematic review and meta-analysis. Journal of epidemiology and community health. NIH Public Access, 65(2), 177-189. https://doi. org/10.1136/jech.2009.095901.

Wardle, J., Carnell, S., \& Cooke, L. (2005). Parental control over feeding and children's fruit and vegetable intake: How are they related? Journal of the American Dietetic Association, 105(2), 227-232. https://doi.org/10.1016/j.jada.2004.11.006.

Watterworth, J. C., et al. (2017). Food parenting practices and their association with child nutrition risk status: Comparing mothers and fathers. Applied Physiology, Nutrition, and Metabolism. NRC Research Press, 42(6), 667-671. https://doi.org/10.1139/apnm2016-0572.

Williams, A., et al. (2018). Dietary outcomes of overweight fathers and their children in the Healthy Dads, Healthy Kids community randomised controlled trial. Journal of Human Nutrition and Dietetics, 31(4), 523-532. https://doi.org/10.1111/jhn.12543.

Yee, A. Z. H., et al. (2017). The influence of parental practices on child promotive and preventive food consumption behaviors: A systematic review and meta-analysis. International Journal of Behavioral Nutrition and Physical Activity, 14(47), https://doi. org/10.1186/s12966-017-0501-3.

Zhang, L., \& McIntosh, W. A. (2011). Children's weight status and maternal and paternal feeding practices. Journal of Child Health Care. SAGE PublicationsSage UK: London, England, 15(4), 389-400. https://doi.org/10.1177/1367493511414448.

Zuercher, J. L., Wagstaff, D. A., \& Kranz, S. (2011). Associations of food group and nutrient intake, diet quality, and meal sizes between adults and children in the same household: A cross-sectional analysis of U.S. Households. Nutrition Journal, 10(1), 131. https://doi.org/10.1186/1475-2891-10-131. 